\title{
Factors Influencing Length of Hospital Stay for Individuals Diagnosed with Type II Diabetes
}

\author{
Loren Nicole Torres ${ }^{\mathrm{a}}$, Dr. Steve Blanchard ${ }^{\mathrm{b}}$ and Dr. Sara Volk ${ }^{\mathrm{a}}$
}

Type II diabetes has become a topic of overwhelming interest in our society. Using results from the 2007 National Hospital Discharge Survey (NHDS), we present a cross-sectional analysis of diabetes in relation to length of hospital care. The NHDS includes a sample of persons discharged with the diagnosis of diabetes $(n=36,000)$. We filtered the sample from the NHDS aggregate (limited to ICD-9-CM codes 250.00 and/or 250.02) to identify the subpopulation of admissions with uncomplicated Type II diabetes. Our study focused on the number of days of care in the hospital as our dependent variable, and its relationship to our predictive variables: sex; age; marital status; method of payment; and type of admission. We examined this data by conducting descriptive, explanatory, and predictive analyses (including linear and logistic regression). Our analysis has identified a number of groups who are statistically-significantly more likely to have longer hospital stays, including: females as opposed to males, patients who were single as opposed to those who were married, patients who were older, those who arrived under emergency admission as opposed to those who were non-emergency, and patients using government insurance as opposed to private forms of insurance. The significance of this study is that it enables hospitals to better predict the demand for hospital resources among their population of patients with Type II diabetes.

Keywords: type II diabetes, hospital days of care

\section{Background}

Type II diabetes is a chronic, potentially life-threatening disease in which the blood glucose levels are too high, leading to a host of physiologic pathologies. Under normal body conditions, insulin (secreted by the beta cells in the pancreas) is responsible for lowering blood sugar levels by moving glucose from the blood into cells for energy storage. Those diagnosed with type II diabetes have insulin-resistant cells that not respond appropriately, and may also produce lower levels of insulin than normal. This failure to respond appropriately to insulin signaling means that they have difficulty moving glucose from the bloodstream into fat, liver or muscle cells, leaving high blood levels of sugar. A broad spectrum of pathologies can result from the increased blood sugar, including neuropathy, kidney failure, cardiovascular disease, and other vascular pathologies (Crawford, 1997). Although the specific cause for type II diabetes is unclear, there is a strong positive correlation with obesity.

A report from the Center for Disease Control and Prevention National Diabetic fact sheet, estimates that 25.8 million people (8.3\% of the US population) suffer from diabetes, costing Americans and estimated $\$ 174$ billion dollars. Ninety to ninety-five percent of diabetics have type II diabetes (CDC, 2008). Another report from the Centers for Disease Control and Prevention, estimates that there will be 300 million diabetics worldwide by 2020. Clearly, this is becoming an international epidemic as well.

\section{Introduction}

Given the increasing impact type II diabetes is having on our collective health and pocketbook, the purpose of our study was to examine the strength of correlations between length of diabetes-related hospital stay and a variety of factors to identify subpopulations that are at higher risk for longer hospital stays. A better understanding of who is more likely to have a longer stay can guide future research and ultimately improve efforts to reduce the impact of the disease. To our knowledge, this is the first such study done pertaining to this specific population.

Our data came from the 2007 National Hospital Discharge Survey (NHDS). About 36,000 patients were filtered from the aggregate using ICD-9-CM codes 250.00 and/or 250.02 as any diagnosis. Our study used univariate, bivariate, and multivariate statistical analyses to examine length of stay (measured by days of care) in relation to sex, age, and marital status, type of admission and method of payment.

Previous work has found, overall, that discharges associated with diabetes increased $65.3 \%$ between 1993 and 2006 (Lee et al. 2011). They found women had higher rates of hospitalizations associated with diabetes compared to men. However, unlike our data, this analysis was done using a National Inpatient Sample (NIS), rather than the National Hospital Discharge Survey. In addition, this study did not examine factors such as social factors such as marital status and method of payment.

The NHDS is an annual survey of short-stay hospitals nationwide that is performed and collected by the National Center for Health Statistics at the Centers for Disease Control and Prevention. To restrict our dataset to diabetes-related admissions, we filtered using two ICD-9-CM codes: 250.00 and 250.02. The code 250.00 accounts for diabetes mellitus without complication Type II or unspecified type not stated as uncontrolled and code 250.02 which describes diabetes mellitus without mention of complication. Due to the specificity of the ICD-9 code listing, we chose only to sort for these cases to minimize complications and allow for a sample that would most accurately represent a population with only

a. Department of Math and Science, Our Lady of the Lake University, San Antonio, TX

b. Department of Applied Social and Cultural Sciences, Our Lady of the Lake University, San Antonio, TX 
type II diabetes. Only information from the year 2007 was accessed and analyzed. For 2007, 422 hospitals responded to the survey and about 366,000 discharges were obtained. Of these, about 36,000 were diagnosed with Type II diabetes upon admittance. Thirty-six variables were included in the 2007 NHDS data file documentation; however, we only examined patient age, sex, marital status, type of admission and source of admission as possible predictor variables for length of stay (reported in days of care). Understanding characteristics of individuals who are more likely to have longer diabetes-related hospital stays can be of tremendous assistance to public health professionals and clinicians, permitting them to better prepare for and better care for those.

\section{Research Question}

What factors account for the variation in the length of hospital stay for those diagnosed with diabetes?

\section{Hypotheses:}

- Sex: Women are more likely to have longer stays in the hospital than men. Literature has shown that women are more likely to be admitted to the hospital with the diagnosis of diabetes than men, thus possibly giving rise to the fact that they could be more critical and thus having longer hospital stays.

- Marital Status: Single individuals are more likely to have longer stays than individuals who are married. Without a partner or significant other to care for them, we predict single persons would be more likely to be admitted to the hospital with more critical illness. An individual who is married may be more likely to have a spouse or partner to urge them to visit the hospital sooner, thereby curtailing length of stay.

- Age: Persons who are older are more likely to have longer stays than persons who are younger because older people are more likely to have more serious illness, and are likely to be slower to recover from illnesses.

- Type of Admission: Persons admitted by emergency are more likely to have longer stays than those admitted as urgent or elective by definition of triage, because they are more likely to have more serious illness that may take longer to recover from.

- Method of payment: Persons for whom the payment of care is "public" (public forms of insurance, including Medicare and Medicaid) are more likely to have longer hospital stays than those paying through private insurance. The population using Medicare or Medicaid may have less access to preventative health care that identifies a medical problem before it becomes serious compared with those who have private health insurance.

\section{Results}

We examined the data for correlations between length of stay and sex, age, marital status, type of admission and source of admission. Research methods include univariate descriptive analysis, bivariate explanatory analysis and multivariate predictive analysis. Our inferential findings are found within $95 \%$ confidence intervals, and calculated using the software PASW Statistics Version 18. Data tables/figures that are not included in this paper are available upon request.

\section{Univariate Descriptive Analyses}

We found, from our 36,188 cases, the average length of stay in the hospital is 4.44 days, with a median of 3.00 (Figure 1). Through our descriptive analysis, we also found there is a greater percentage of women who were discharged from the hospital with diabetes as a diagnosis. Most of the diabetic patients from the 2007 NHDS population use public insurance (Medicaid/Medicare). The average age of women in this population is 65.7 years, and the average age of men is 64.5 years. $98.6 \%$ of these patients stayed in the hospital more than one day. The majority of individuals were admitted by triage under emergent care $(59.2 \%)$ followed by elective admission $(21.5 \%) .63 \%$ of the individuals did not state their marital status; however, of those who identified their status, $48 \%$ were married, $19 \%$ single, $22 \%$ widowed, and $11 \%$ were either separated or divorced. Those whose marital status is included accouted for 13,000 patients.

\section{Bivariate Explanatory Analyses}

First, we examined the relationship between length of stay and sex. We found the mean length of stay in our diabetes data set was 0.18 days longer for females (4.52 days) versus males (4.34 days). Analysis of variance (ANOVA) showed that this modest difference was statisticallysignificantly different $(\mathrm{p}$-value $=.000$ and $\mathrm{F}=14.414)$. From these calculations, we conclude that our best estimate of true relationship between length of stay and sex is that women have 0.18 ( $=4 \%$ longer) longer hospital stays than men.

An analysis of length of hospital stay by marital status (married versus all categories of not married) revealed that persons who are single are significantly more likely to have longer hospital stays (mean 4.75 days) than those who are married (mean 4.09 days) ( $\mathrm{p}$-value $=0.000$ and $\mathrm{F}=75.136$ ). Therefore, the best estimate of the true difference in length of stay is that individuals who are not married have 0.66 more days of care (16\% longer) than those who are married.

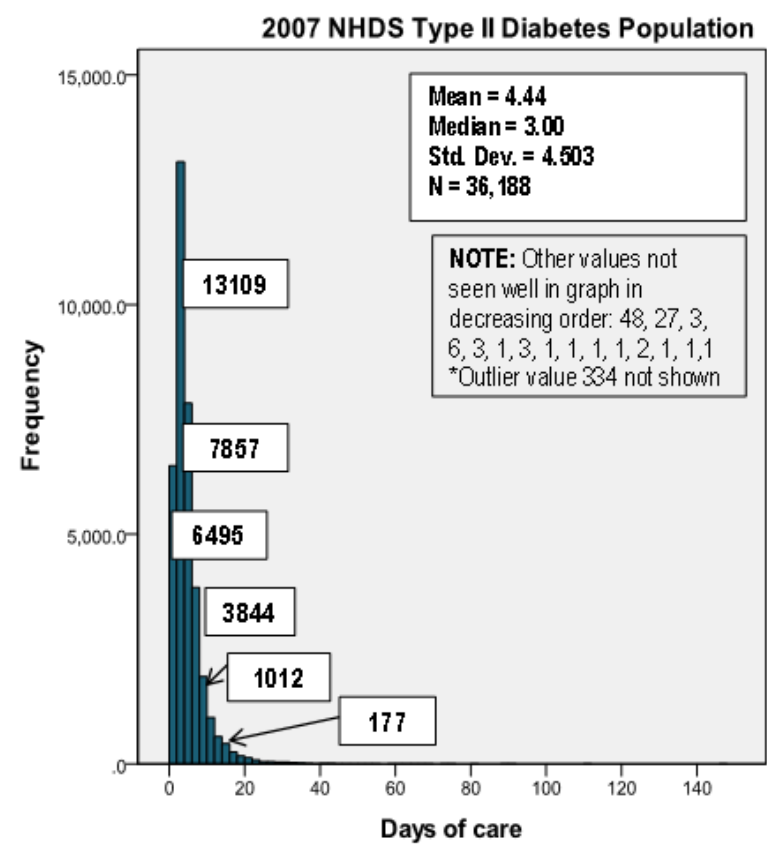

Figure 1: 2007 NHDS Type II Diabetes population 
Type of admission was classified as emergent, urgent or elective. The mean stay for someone who was admitted as emergent was 4.49 days, while for urgent admission, the mean was 4.45 days and for elective admission the mean was 4.24 days. The p-value (.000) gave us more than $99 \%$ confidence that there is significant difference between at least 2 of these three categories (F-value=9.189). Notably, however, there is overlap of the $95 \%$ confidence intervals between those admitted as emergent and those admitted as urgent. Still, the best estimate of true difference allows us to conclude that someone admitted as emergent will have 0.25 more days of care versus someone admitted as urgent, although this is not statistically significant.

The ANOVA of days of care by source of admission also supported our hypothesis that there is a significant difference between those admitted as emergency and those that were not: p-value .000 and F-value 224.189. From our best point estimate, we can conclude a person who comes to the hospital via the emergency room without doctor's orders, is more likely to have 2.54 more days of care compared with someone who is admitted by a physician referral.

In our diabetic population, the mean length of stay is 4.44 days and the mean age is 65.15 . We found a weak positive correlation between age and length of stay, with a Pearson Correlation of 0.052 significant at the 0.01 level (2tailed).

We also examined the relationship between type of admission and sex. We found a higher percentage of women $(61.8 \%)$ were admitted as emergent compared to men $(60.7 \%)$. Of the males, $16.9 \%$ were admitted as urgent with $16.1 \%$ of women. As elective, $22.5 \%$ of men were admitted and $22.0 \%$ of women. The chi square value for these calculations is 5.624. Our cross tabulations of type of admission by marital status resulted in a higher percentage of single people $(66.5 \%)$ admitted as emergent as opposed to those who were married, and also admitted as emergent (58.0\%). The percentages of those single admitted as urgent were $15.7 \%$ and elective were $17.7 \%$. The ratios for married individuals admitted were $16.9 \%$ urgent and $25.1 \%$ elective. The chi square for this cross tab is 121.339 .

\section{Multivariate Predictive Analyses}

Ultimately, after assessing which variables support our hypothesis and are statistically significant, we perform predictive analyses. In doing our predictive analyses, we used both linear and logistic regression (Agresti, July 2011). We decided to use both of these procedures to analyze the same questions, because each contributes a different perspective on our research question. Linear regression allows us to predict the average of days of care for any number of combinations of our predictor variables. In the linear regression, we retain continuous variation of days of care, as opposed to logistic regression in which we use a dichotomous variable of days of care -the High as the median or higher; Low as below the median). By using logistic regression we are able to predict probabilities and odds from our model. Our linear regression follows the formula: $\mathrm{y}=\mathrm{x}_{\mathrm{i}}$, where $\mathrm{y}=$ days of care. Calculations are shown in Table 1.
Table 1: Linear Regression Coefficients

\begin{tabular}{|c|c|c|c|}
\hline Variable & Coefficient & Type & Label \\
\hline $\begin{array}{c}\text { Days of } \\
\text { Care }\end{array}$ & & Scale & Continuous \\
\hline Age & 0.016 & Continuous & Continuous \\
\hline Sex & 0.087 & Categorical & $\begin{array}{c}\text { Female : } 1 \\
\text { Male : } 0\end{array}$ \\
\hline $\begin{array}{c}\text { Marital } \\
\text { status }\end{array}$ & 0.539 & Categorical & $\begin{array}{c}\text { Single : } 1 \\
\text { Married : } 0\end{array}$ \\
\hline $\begin{array}{c}\text { Type of } \\
\text { admission }\end{array}$ & -0.072 & Categorical & $\begin{array}{c}\text { Emergent : } 1 \\
\text { Non- } \\
\text { emergent: } 0\end{array}$ \\
\hline $\begin{array}{c}\text { Method of } \\
\text { pay }\end{array}$ & .0416 & Categorical & $\begin{array}{l}\text { Public : } 1 \\
\text { Private : } 0\end{array}$ \\
\hline Constant & & & \\
\hline
\end{tabular}

Linear regression for female age 50

$\mathrm{Y}=$ sex female + age at $50+$ marital status single + type of admission emergent + method of pay public

$\mathrm{Y}=2.838+0.087+0.016(50)+0.539-0.072+0.416$

$\mathrm{Y}=2.838+0.087+0.8+0.539-0.072+0.416$

$\mathrm{Y}=4.608$

A single woman at the age of 50, whose primary method of payment is public insurance, and is admitted into the hospital as emergent is predicted to stay in the hospital for 4.6 days.

Linear regression for a male age 50

$\mathrm{Y}=$ sex male + age at $50+$ marital status single + type of admission emergent + method of pay public

$\mathrm{Y}=2.925-0.087+0.016(50)+0.539-0.072+0.416$

$\mathrm{Y}=2.925-0.087+0.8+0.539-0.072+0.41$

$\mathrm{Y}=4.515$

A single man at the age of 50, whose primary method of payment is public insurance, and is admitted into the hospital as emergent is predicted to stay in the hospital for 4.5 days.

The second predictive mechanism is logistic regression. The coding and calculations are shown in Table 2.

Table 2: Logistic Regression Coefficients

\begin{tabular}{|c|c|c|c|}
\hline Variable & Coefficient & Type & Label \\
\hline $\begin{array}{l}\text { Days of } \\
\text { Care }\end{array}$ & & Categorical & $\begin{array}{l}\text { High: } 3 \text { or greater } \\
\text { Low: Lower than } 3\end{array}$ \\
\hline Age & 0.014 & Continuous & Continuous \\
\hline Sex & 0.136 & Categorical & $\begin{array}{c}\text { Female : } 1 \\
\text { Male : } 2\end{array}$ \\
\hline $\begin{array}{c}\text { Marital } \\
\text { status }\end{array}$ & 0.254 & Categorical & $\begin{array}{c}\text { Single : } 1 \\
\text { Married : } 2\end{array}$ \\
\hline $\begin{array}{c}\text { Type of } \\
\text { admission }\end{array}$ & 0.080 & Categorical & $\begin{array}{c}\text { Emergent: } 1 \\
\text { Non-emergent: } 2\end{array}$ \\
\hline $\begin{array}{l}\text { Method } \\
\text { of pay }\end{array}$ & 0.201 & Categorical & $\begin{array}{l}\text { Public : } 1 \\
\text { Private : } 2\end{array}$ \\
\hline Constant & & & \\
\hline
\end{tabular}


Logistic regression for a female age 60

$\mathrm{P}(\mathrm{Y}=$ days of care $)={ }_{\mathrm{e}}$ constant + sex female + age at $60+$ marital status single + type of admission emergent + method of pay public/ $\left(1+{ }_{\mathrm{e}}\right.$ constant + sex female + age at $60+$ marital status single + type of admission emergent + method of pay public)

$\mathrm{P}(\mathrm{Y}=1)=\left[_{\mathrm{e}}-0.780+0.136+0.014(60)+0.254+0.080+\right.$ $0.201] / 1+[\mathrm{e}-0.780+0.136+0.014(60)+0.254+0.080+$ 0.201]

$\mathrm{P}(\mathrm{Y}=1)=2.07716 / 1+2.07716$

$\mathrm{P}(\mathrm{Y}=1)=2.07716 / 3.07716$

$\mathrm{P}(\mathrm{Y}=1)=0.6750$

The estimated odds for a single woman, 60 years of age, admitted as emergent and paid with public insurance is .68. Otherwise said, 68 of every 100 women who meet the criteria above will need high days of care.

Logistic regression for a female age 30

$\mathrm{P}(\mathrm{Y}=1)=[\mathrm{e}-0.780+0.136+0.014(30)+0.254+0.080+$ $0.201] / 1+[\mathrm{e}-0.780+0.136+0.014(30)+0.254+0.080+$ $0.201]$

$\mathrm{P}(\mathrm{Y}=1)=1.3648 / 1+1.3648$

$\mathrm{P}(\mathrm{Y}=1)=1.3648 / 2.3648$

$\mathrm{P}(\mathrm{Y}=1)=0.5771$

The estimated odds for a single woman, 30 years of age, admitted as emergent and paid with public insurance is .58 . Otherwise said, 58 of every 100 women who meet the criteria above will need high days of care.

Following the same calculations for males with all the same variables as from the above equation is as follows.

Logistic regression for male age 60

$\mathrm{P}(\mathrm{Y}=1)=[\mathrm{e}-0.780-0.136+0.014(60)+0.254+0.080+$ $0.201] / 1+[\mathrm{e}-0.780-0.136+0.014(60)+0.254+0.080+$ 0.201]

$\mathrm{P}(\mathrm{Y}=1)=1.5825 / 1+1.5825$

$\mathrm{P}(\mathrm{Y}=1)=1.5825 / 2.5825$

$\mathrm{P}(\mathrm{Y}=1)=0.6128$

The estimated odds for a single male, 60 years of age, admitted as emergent and paid with public insurance is .61. Otherwise said, 61 of every 100 men who meet the criteria above will need high days of care.

Logistic regression for male age 30

$\mathrm{P}(\mathrm{Y}=1)=[\mathrm{e}-0.780-0.136+0.014(30)+0.254+0.080+$ $0.201] / 1+[\mathrm{e}-0.780-0.136+0.014(30)+0.254+0.080+$ $0.201]$

$\mathrm{P}(\mathrm{Y}=1)=1.0398 / 1.0398+1$

$\mathrm{P}(\mathrm{Y}=1)=1.0398 / 2.0398$

$\mathrm{P}(\mathrm{Y}=1)=0.5098$

The estimated odds for a single male, 30 years of age, admitted as emergent and paid with public insurance is .51. Otherwise said, 51 of every 100 men who meet the criteria above will need high days of care.

\section{Conclusion}

From these findings, our research has revealed an enormous breadth of information. We have been able to accept every one of our research hypotheses and reject the null. For example, we found that within $95 \%$ confidence intervals, women who are single, older, admitted as emergent, and for whom payment is public are more likely to have a longer length of stay than men with similar characteristics. Many literature articles have concurred with the understanding that women generally have, "higher rates of hospitalizations associated with diabetes compared with men" (Lee \& Davis, July 2011). In addition, days of care showed a positive correlation with age -not particularly surprising, older individuals are more likely to have medical complications that would lead to longer hospitalization days. We also found individuals who were single were more likely to have longer days of care in the hospital versus those who were married. We believe people who are single have higher number of days in the hospital because they delay care as a result of not having a partner who prompts them. Persons with a spouse or partner are more likely to be admitted electively rather than by EMS. With this rationale in mind, we were able to conclude that perhaps the reason why there were significantly higher numbers of singles admitted into the hospital versus those who were married, is due to delay of admittance. Likewise, those who entered the hospital as emergent, followed our prediction that those individuals are more likely stay in the hospital for longer periods of time because they were admitted as a more critical medical emergency as opposed to someone who chose to visit the hospital as elective. Our findings have also indicated those who paid with public insurance have higher mean days of care in the hospital versus those who use some other form of private healthcare. With reservations, the method of payment could be used in some ways as a surrogate for socioeconomic status (SES) linked with social status, education and income. This being said, our research has shown individuals who have paid for hospital services with public forms of insurance (Medicare/Medicaid), on average have higher days of care than those who pay with private insurance. Nonetheless, being an extremely multifaceted variable, SES in research must be "measuring as much relevant socioeconomic information as possible" (Braveman et al. July 2011).

Unfortunately, due to our data set limitations, we did not have access to patient income or education. However, since we had such a large sample size, our results and research have shown to be statistically significant. Our findings have unearthed new information regarding the description of this population, in addition to the probability of length of hospital stay by certain individual characteristics. Though the raw numbers may not seem astounding at first glance, the estimated odds do seem to spark more attention to a much needed addressing issue. Further study involving other diabetic complications could lead to extensively more knowledge regarding the severity of this disease. Still, our results have provided sound statistically proven data indicating predictive models that will allow researchers, clinicians and hospital administrators to better prepare and care for this rapidly growing population.

\section{References}

Agresti, Alan, and Barbara Finlay. Statistical Methods for the Social Sciences. Upper Saddle River, NJ: Prentice Hall, 1997. Print.

Alexander, L., \& Wilfert, R. A. (n.d.). Data Analysis Basics : Variables and Distribution. Epidemiology, 3(5). 
Anderson, M., \& Wilfert, R. (1999). Data Analysis : Simple Statistical Tests. Focus, 3(6).

Braveman, P. a, Cubbin, C., Egerter, S., Chideya, S., Marchi, K. S., Metzler, M., \& Posner, S. (2005). Socioeconomic status in health research: one size does not fit all. JAMA : the journal of the American Medical Association, 294(22), 2879-88. doi:10.1001/jama.294.22.2879

Carolina, N. (n.d.). National Network of Public Health Training Centers Free Online Training P U B L I C H E A L T H 101 Introduction to Public Health in National Network of Public Health Training Centers Free Online Training. Public Health, 0-1.

Centers for Disease Control and Prevention. National diabetes fact sheet: general information and national estimates on diabetes in the United States, 2007. Atlanta, GA: U.S. Department of Health and Human Services, Centers for Disease Control and Prevention, 2008.

Cheng, D. (2005). Prevalence, predisposition and prevention of type II diabetes. Nutrition \& metabolism, 2, 29. doi:10.1186/1743-7075-2-29

Documentation, D. F. (2010). 1979-2007 Multi-Year Public Use Data File Documentation 1979-2007 Multi-Year Public Use Data File Documentation. International Classification, (July).

Festa, A., Agostino, R. D., Tracy, R. P., \& Haffner, S. M. (2002). Plasminogen Activator Inhibitor-1 Predict the The Insulin Resistance Atherosclerosis Study. Public Health, 51(May 2001).

Guilherme, A., Virbasius, J. V., Puri, V., \& Czech, M. P. (2008). Adipocyte dysfunctions linking obesity to insulin resistance and type 2 diabetes. Nature reviews.Molecular cell biology, 9(5), 367-77. doi:10.1038/nrm2391

Health, F. (2010). National Hospital Discharge Survey Data Documentation 2007. Statistics, (April).

International Classification of Diseases, 9th Revision, Clinical Modification, 6th edition. U.S. Department of Health and Humans Services, National Center for Health Statistics, Health Care Financing Administration. 2006.

Kumar, Vinay, Ramzi S. Cotran, Stanley L. Robbins, and Vinay Kumar. Basic Pathology. Philadelphia: W.B. Saunders, 1992. Print.

Lee, Joyce M., Matthew M. Davis, Acham Gebremariam, and Catherine Kim. "Age and Sex Differences in Hospitalizations Associated with Diabetes." Journal of Women's Health 19.11 (2010): 2033-042. Academic Search Elite. Web. 17 July 2011.

Prevalence, E. C.-level, \& States, U. (2009). Morbidity and Mortality Weekly Report American Diabetes Month Estimated County-Level Prevalence of Diabetes and Obesity - department of health and human services. Diabetes, 58(45).

U.S. Department of Health and Human Services Centers for Disease Control and Prevention National Center for Health Statistics. 2007 National Hospital Discharge Suvey Public Use Data File Documentation. Rep. Hyattsville, 2010. ftp://ftp.cdc.gov/pub/Health_Statistics/NCHS/Datasets/N HDS/nhds07/
U.S. Department of Health and Human Services Centers for Disease Control and Prevention National Center for Health Statistics. 2007 National Hospital Discharge Suvey Public Use Data File. "NHDS07.PU.TXT" (June 12, 2011). FTP to ftp <ftp://ftp.cdc.gov/pub/Health_Statistics/NCHS/Dataset_ Documentation/NHDS/> 